\title{
Cocaína: origens, passado e presente
}

\author{
Flávia Campos Bahls \\ Saint-Clair Bahls \\ Universidade Federal do Paraná
}

\begin{abstract}
Resumo
Ciclos de abuso de cocaína têm ocorrido através do mundo por mais de cem anos. O presente trabalho tem por objetivo colaborar pelo aprofundamento da investigação histórica desse tema. Os autores remontam o uso das folhas de coca, pelos índios da América do Sul, em aproximadamente 500 a.C. No século XIX, a cocaína alcançou os países desenvolvidos da época, e foi introduzida no contexto social e médico. É descrita a trajetória da cocaína no Brasil nos últimos anos, considerando-se o consumo em estudantes de $1^{\circ}$ e $2^{\circ}$ grau, internações hospitalares e crianças em situação de rua. $\mathrm{O}$ uso abusivo por um número crescente de pessoas traz conseqüências assustadoras para a saúde do indivíduo e para a sociedade como um todo.
\end{abstract}

Palavras-chave: abuso de drogas; cocaína; história.

\begin{abstract}
Cocaine: origins, the past and the present

Cycles of cocaine abuse have occurred throughout the world for more than 100 years. This paper intends to provide a historical background to the subject. The authors retrace about coca leaves use by the South America natives dating from approximately 500 b.C. In the $19^{\text {th }}$ century, coca reached the developed countries and it was introduced in the social and medical context. This review describes the trajectory of cocaine in Brazil in the last years, respecting abuse and dependence among hospitalized patients, high school and college students and street children. The increase of the drug abuse results in alarming conseqüences to the users' health as well as for the whole society.
\end{abstract}

Keywords: cocaine; drug abuse; history.

Ciclos de abuso de cocaína têm ocorrido através do mundo por mais de cem anos (Fischman \& Haney, 1999). A cocaína é o principal alcalóide do arbusto Erytroxylon coca que é encontrado ao leste dos Andes e acima da Bacia Amazônica (Leite, 1999). É cultivada em clima tropical a altitudes que variam entre 450 m e 1.800 m acima do nível do mar (Ferreira \& Martini, 2001).

A cocaína tem uma origem histórica bastante rica. Embora o alcalóide não tenha sido extraído até a metade do século XIX, sítios arqueológicos no Peru encontraram folhas de coca colocadas junto às tumbas de sepultamento, testemunhando seu uso há mais de 2.500 anos. Até hoje os índios peruanos colocam as folhas de coca junto com os mortos acreditando ser um item necessário para o "além da vida" (Weiss, Mirin \& Bartel, 1994).

A palavra coca deriva da língua aymara, significando planta ou árvore. A civilização inca, originária da região de Cuzco, cultivou e estabeleceu o consumo da coca, conservando-se algumas lendas distintas sobre sua origem: na tradição incaica, o primeiro inca, Mango Capac, filho do Sol, desceu do céu sobre as águas do lago Titicaca para ensinar aos homens as artes, a agricultura e presenteá-los com as primeiras sementes, tornando-os capazes de suportar a fadiga e a fome, enquanto, para os índios yunga o arbusto da cocaína possibilitou a derrota do deus maligno (Ferreira \& Martini, 2001; Leite, 1999). Outros autores, como Weiss e colaboradores (1994) referem que em regiões onde crescia ou plantava-se o arbusto da cocaína, os habitantes indígenas também acreditavam na origem divina deste arbusto, tanto que os sacerdotes destas tribos mantiveram durante séculos a tradição de reverenciar a seus deuses usando folhas de coca, tradição esta observada ainda hoje, em contextos religiosos das populações indígenas do Peru, Bolívia, Colômbia e Equador.

Desde a antigüidade o uso das folhas encontra, então, razões religiosas ou relaciona-se ao aumento da capacidade de trabalho devido à ação psicoativa pro- 
porcionada pelo alcalóide contido nas folhas, a cocaína. A antiga prática de mascar as folhas ainda hoje é reconhecida por diminuir ou tirar a fome e a fadiga (Gold, 1993). Temas de sedução e perigo são encontrados em associação com a cocaína, como, por exemplo, a lenda sobre o lugar no qual cresceu a planta, que teria sido onde foi enterrada uma bonita mulher, executada por adultério e cortada ao meio (Weiss e cols., 1994).

Os espanhóis, conquistadores da América no século XVI, encontraram a civilização inca e admiraram-se com suas riquezas botânicas. Médicos e farmacêuticos espanhóis vieram para a América aprender com os indígenas e levar as práticas medicinais para a Europa. Assim, as folhas de coca passaram para o continente europeu. Entretanto, provavelmente devido à degeneração da substância psicoativa contida nas folhas, que ocorria durante o transporte a partir das Américas, não ocorreu a difusão e o consumo na Europa neste período (Weiss e cols., 1994).

$\mathrm{Na}$ América colonial o consumo se popularizou entre os índios, pois anteriormente o uso era privilégio da nobreza inca. A percepção de que os índios não conseguiam realizar o trabalho pesado sem o uso da coca sobrepujou a oposição da Igreja católica ao consumo. Em 1569, o rei espanhol Felipe II declarou que o ato de mascar coca era essencial à saúde do índio (Bucher, 1992; Ferreira \& Martini, 2001). Os nativos da região fronteiriça da Venezuela, Colômbia e Brasil mantêm o hábito até hoje de mascar o epadu, que é a folha torrada de coca misturada a elementos alcalinos.

\section{A cocaína na Europa e nos Estados Unidos}

O químico alemão Friedrich Gaedecke em 1855 extraiu o ingrediente ativo da folha da coca, que ele chamou de erythroxylon. Em 1859, outro químico alemão, Albert Niemann, isolou o alcalóide a partir das folhas da planta e denominou-o cocaína (Weiss e cols., 1994).

A partir da descoberta dos químicos alemães, a cocaína passou a ser empregada em vários produtos. Em 1863, uma mistura de vinho e folhas de coca, Vin Tonique Mariani - Coca du Perou, era produzido em Paris por Angelo Mariani. Fenômeno de sucesso, recomendado por dois papas (um deles papa Leão XIII que condecorou o vinho), médicos (como Gilles de la Tourette ), reis e virtualmente todas as personalidades importantes da época, tais como Julio Verne e Thomas Edison (Weiss e cols., 1994). Nesta época, nos Estados Unidos, extratos de coca eram prescritos para enfermidades de difícil tratamento tais como alcoolismo e morfinismo, sendo que esses preparados facilitaram o caminho para o uso da cocaína em sua forma pura a partir de 1880 (Carlini-Cotrim, 1995).
Nos Estados Unidos, durante praticamente todo o século XIX, a cocaína foi livre e entusiasticamente comercializada (Leite, 1999; Weiss e cols., 1994). Era vendida nas ruas por 25 centavos de dólar o grama na sua forma pura, ou obtida de modo industrializado pela Parke Davis Company em quinze formas diferentes, tais como cigarros, pó, preparado para injetar e pastilhas, segundo Carlini-Cotrim (1995). Era indicada para dores, cansaços, substituto alimentar, entre outras. Foi entre 1886 e 1900 que a cocaína foi incluída na fórmula do refrigerante Coca-Cola (CarliniCotrim, 1995).

\section{A cocaína na Medicina}

Entre os inúmeros alcalóides da folha de coca, a cocaína representa $80 \%$ do total dos alcalóides. Em pequena proporção encontra-se a nicotina, cafeína e a morfina. Concentrações de tiamina, riboflavina e ácido ascórbico estão presentes. A fórmula exata de sua estrutura química foi descoberta em 1898 (Ferreira \& Martini, 2001).

A cocaína foi distribuída na Europa pelo laboratório Merck no final do século XIX a especialistas para realizarem experimentos com a droga (Leite, 1999). Neste período, Sigmund Freud dedicou-se ao estudo da cocaína. Baseou-se na experiência pessoal de autoadministração e observação de pacientes para os quais prescreveu cocaína. Em julho de 1884 publicou seu famoso livro Über Coca (Sobre a Cocaína) recomendando-a para o tratamento da depressão, do nervosismo, doenças digestivas, alcoolismo, adição à morfina e asma. Freud administrou cocaína a seu amigo Dr. Ernst von Fleischl Marxow com o intuito de tratar as dores que ele apresentava como resultante da amputação da perna e subseqüente dependência de morfina. Rapidamente Fleischl passou a injetar crescentes quantidades de cocaína subcutânea, disso resultando um quadro paranóide, com delírios e tornando-se então intratável (Gold, 1993). Freud foi acusado de irresponsabilidade pela comunidade científica da época por seu entusiasmo pela cocaína (Weiss e cols., 1994). Em 1887, publica Fissura e Medo da Cocaína, descrevendo os sintomas paranóides, as alucinações e a deterioração física e mental associada ao consumo repetido. O próprio autor reputava o período de 1884-1885 como "o ano mais sombrio e mais fracassado de minha vida" (Gold, 1993).

A cocaína foi empregada também como anestésico, inicialmente por Karl Koller que acabou desenvolvendo dependência e chegando a ser chamado de 'Coca Koller' (Weiss e cols., 1994). O conhecido pai da cirurgia moderna, Wiliam Halsted e um dos fundadores da Faculdade de Medicina da Universidade de Johns Hopkins, procurou estabelecer o uso da droga como anestésico local. Obteve sucesso no bloqueio da 
dor dando início à era das cirurgias oculares, entre outras. Halsted, no intuito de pesquisar a substância passou a administrar cocaína em si mesmo, desenvolvendo dependência. Na tentativa de tratar o problema com a cocaína, utilizou-se de morfina, tornando-se, também, dependente de morfina até o final de sua vida (Ferreira \& Martini, 2001).

\section{A cocaína no Brasil}

No Brasil, a cocaína era legalmente comercializada no início do século XX, como parte integrante na formulação de remédios ou na sua forma pura. Por exemplo, propaganda publicada na Gazeta Médica de São Paulo, em 1910, anunciava a venda de cocaína para laringites, tosses etc., dizendo que quem comprasse na farmácia um frasco ganharia uma caixinha para guardar os comprimidos no bolso (Carlini, Noto, Galduróz \& Nappo, 1996).

Em 1914, no contexto norte-americano da LeiSeca é assinado o chamado Harrison Act, que restringiu a disponibilidade da cocaína para a população. A onda de consumo de cocaína observado entre o final do século XIX e início do século XX entra em declínio. Segundo Leite (1999) a visão social da cocaína transformou-se em 30 anos (desde 1884), de um tônico anunciado sem efeitos colaterais para uma droga com restrições muito severas.

No início do século XX a imprensa e a sociedade brasileira, sob influência das questões norte-americanas, passaram, também, a enfocar o uso de cocaína com preocupação. No artigo "Visão histórica sobre o uso de drogas: passado e presente; Rio de Janeiro e São Paulo" de Carlini e cols. (1996) desenvolve-se a idéia de que, em torno de 1914, a cocaína passou por uma mudança de lugar no imaginário social brasileiro e começou a ser vista como um comércio perigoso, que ameaçava a integridade e a vida das pessoas. Acreditam os autores que devido aos clamores da imprensa e da sociedade em geral, o Congresso Nacional aprovou o Decreto-lei 4.292, em 06/07/1921 que, entre outras coisas, estabeleceu: a) penalidades (multa e prisão) para as contravenções na venda de cocaína e outras drogas; b) criação de estabelecimento especial para tratamento de dependentes com duas seções, uma para internados judiciários e outra para internados voluntários.

Interessante notar que nos quarenta anos seguintes, pouca cocaína foi apreendida pela polícia brasileira, bem como, as internações por uso dessa substância foram quase inexistentes (Carlini \& cols., 1996). Em 1962 é feito o primeiro levantamento nacional brasileiro sobre internações por dependência de drogas. $\mathrm{O}$ Brasil então com cerca de 70 milhões de habitantes teve, em seus 187 hospitais psiquiátricos existentes na época, apenas 4 casos de internação por problemas decorrentes de uso de cocaína, contra mais de oito mil casos de internação por alcoolismo (Carlini \& cols., 1996).

Entretanto, observou-se o ressurgimento da disponibilidade e do consumo da cocaína no início de 1970 nos Estados Unidos da América, e alguns fatores para a compreensão deste fenômeno são propostos por Weiss e cols. (1994). Primeiro, uma considerável parte da população nasceu e cresceu em meio ao consumo de drogas. O consumo de maconha e alucinóge-

nos na década de 1960 por um grande número de jovens norte-americanos resultou na diminuição do temor das restrições legais. Segundo, desenvolveu-se um conceito social e médico de que o consumo de cocaína apresentava segurança em relação às consequiências e não envolvia potencial de abuso ou dependência. Socialmente ocorreu uma apologia sobre o seu uso e artigos populares em revistas como Time e Newsweek sugeriam ser uma das maravilhas do mundo. Segundo Leite (1999) a psiquiatria norte-americana considerou a cocaína como um euforizante benigno e se consumida duas ou três vezes por semana não causaria sérios problemas.

$\mathrm{O}$ ressurgimento norte-americano do consumo de cocaína implicou, também, o que se observou no Brasil ao final de 1980 e início de 1990, quando constatou-se crescimento do consumo de cocaína na população brasileira (Carlini, Nappo \& Galduróz, 1993; Nappo, 1996; Leite, 1999). Quatro estudos abrangentes realizados sob a direção de E. A. Carlini, através do Centro Brasileiro de Informações sobre Drogas Psicotrópicas (CEBRID) do Departamento de Psicobiologia da Escola Paulista de Medicina, compreendem os levantamentos nacionais sobre uso de drogas em estudantes de primeiro e segundo graus de dez regiões metropolitanas do Brasil (1987, 1989, 1993 e 1997). O uso da cocaína têm demonstrado aumento preocupante, pois apresentou um padrão de consumo (uso na vida $\left.^{1}\right)$ crescente de modo significativo. A cocaína quadriplicou neste período, passando de $0,5 \% \mathrm{em}$ 1987 para 2,0\% em 1997 (Galduróz, Noto \& Carlini, 1997).

Quanto às internações no Brasil por transtornos mentais e de comportamento decorrentes de substâncias psicoativas, no período de 1988 a 1999, as causadas por cocaína e seus derivados foram as que mais cresceram, passando de 0,8\% (em 1988) para 4,6\% (em 1999). Para a maconha, o número de internações diminuiu no final da década de 1980, atravessando a década de 1990 com oscilações (Noto, Moura, Nappo, Galduróz \& Carlini 2002). No entanto, os estudos populacionais apontam para um crescente consumo de 
maconha no Brasil (Galduróz \& cols., 1997; Noto, Nappo, Galduróz \& Carlini, 1997). Este fenômeno, no que diz respeito ao crescimento do consumo por uma lado e a diminuição de internamentos por maconha por outro, poderia estar refletindo um posicionamento menos radical por parte da família e dos profissionais de saúde responsáveis pelo encaminhamento dos casos de consumo de maconha para internação. Outra possível explicação para esta mudança seria a de que o aumento das internações por consumo de cocaína estaria ocultando aquelas por uso de maconha (Noto \& colaboradores, 2002).

Uso na vida é a categoria estabelecida pela Organização Mundial de Saúde (OMS) para o uso de uma substância psicoativa por pelo menos uma vez na vida.

Em populações específicas, como as crianças de rua de grandes cidades, a cocaína é proporcionalmente muito mais consumida (relatos em 46,5\% dessas crianças na cidade de São Paulo (Leite, 1999). Com o surgimento do crack, durante a década de 1990, Nappo (1996) descreve que o consumo de cocaína, na forma de crack ou não, e suas conseqüências, têm crescido substancialmente.

No estudo de Alves (2001), um levantamento em 682 prontuários de adolescentes internados no ano de 1999 por uso de drogas em Curitiba, encontrou-se que as substâncias mais utilizadas foram a maconha $(69,7 \%)$, a cocaína na forma de crack $(49,7 \%)$ e o álcool $(38,8 \%)$, seguidos de cocaína na forma de pó $(28,7 \%)$. Considerando-se a cocaína conjuntamente com seus derivados, no caso o crack, somaria-se então $77,7 \%$ de internações por cocaína e seus derivados. $\mathrm{O}$ estudo levantou alguns prejuízos nestes adolescentes e, o abandono escolar, por exemplo, foi encontrado, através da descrição em prontuários clínicos, em $62,4 \%$ da amostra. Pontuou-se a associação com comportamento anti-social tipo roubo dentro e fora de casa, envolvimento em assaltos e tráfico de drogas.

\section{CONCLUSÃO}

O abuso de uma determinada substância parece ocorrer de modo cíclico (Fischman \& Haney, 1999; Weaver \& Schnoll, 1999). Uma nova droga pode tornar-se popular até alcançar um pico de consumo entre os adictos, freqüentemente gerando pânico na população geral. Entretanto, taxas de abuso declinam gradualmente até uma nova droga começar o ciclo novamente (Weaver \& Schnoll, 1999).

A presente revisão histórica sobre a cocaína procurou delimitar os ciclos de consumo encontrados ao longo do desenvolvimento da humanidade, concluindo-se por uma trajetória desde a antigüidade. Compreendeu-se que as diversas organizações humanas, em diferentes períodos históricos oscilaram entre aceita- ção ou estimulação do uso de cocaína, ou restrições severas ao consumo. As sociedades em momentos de aceitação ou restrição do uso mantêm um conceito acerca da substância e no presente estudo verificou-se, através da revisão da literatura, que os conceitos e funções delegados à cocaína, nos períodos de aceitação do uso, variaram entre religiosos, medicinais, sociais e recreacionais para os períodos de aceitação do uso. De modo diferente, em fases onde ocorre a restrição, a cocaína é relacionada com prejuízos físicos, emocionais, sociais, comportamentais e legais.

O conceito atual, segundo a Organização Mundial de Saúde (2000) é de que a cocaína usada nas suas diversas formas é uma substância que traz um impacto adverso em praticamente todas as áreas da vida do indivíduo, além de que seu uso se inicia principalmente na adolescência quando as competências necessárias para a vida adulta estão se estabelecendo. Para finalizar, sugere-se que uma droga não seja banalizada, nem destinada a funções demonistas, pois o risco que se corre é o de banalizar ou demonizar o ser humano envolvido na problemática do consumo de droga.

\section{REFERÊNCIAS}

Alves, R. (2001). Caracterização dos adolescentes internados por álcool e outras drogas na cidade de Curitiba. Dissertação de Mestrado, Universidade Federal do Paraná. Curitiba, $\mathrm{PR}$.

Bucher, R. (1992). Drogas e drogadição no Brasil. Porto Alegre: Artes Médicas.

Carlini-Cotrim, B. (1995). Movimentos e discursos contra as drogas: O caso da sociedade norte-americana. Revista Brasileira de Psiquiatria da Associação Psiquiatrica de La America Latina, 17(3), 93-101.

Carlini, E. A.; Nappo, S. A. \& Galduróz, J. C. (1993). A cocaína no Brasil ao longo dos últimos anos. Revista Brasileira de Psiquiatria da Associação Psiquiatrica de La America Latina, 15(4), 121-127.

Carlini, E. A; Noto, A. R; Galduróz, J. C. F \& Nappo, A. S. (1996). Visão histórica sobre o uso de drogas: passado e presente; Rio de Janeiro e São Paulo. Jornal Brasileiro de Psiquiatria, 45(4), 227-236.

Ferreira, P. E. M \& Martini, R. K. (2001). Cocaína: lendas, história e abuso. Revista Brasileira de Psiquiatria,23(2), 96-99.

Fischman, M. W \& Haney, M. (1999). Neurobiology of stimulants. Em M. Galanter \& H. D. Kleber (Orgs.), Textbook of substance abuse treatment (p. 21-31). ( $2^{\mathrm{a}}$ ed.), Washington, DC: The American Psychiatric Press.

Galduróz, J. C. F.; Noto, A. R. \& Carlini, E. A. (1997). IV Levantamento sobre o uso de drogas entre estudantes de $1^{\circ}$ e $2^{\circ}$ graus em 10 capitais brasileiras. São Paulo: Centro Brasileiro de Informações sobre Drogas Psicotrópicas - CEBRID, Departamento de Psicobiologia, Escola Paulista de Medicina, Universidade Federal de São Paulo.

Gold, M. S. (1993). Cocaine. New York: Plenum Medical Book Company. 
Leite, M. C. (1999). História da cocaína. Em M. C. Leite \& A.G. Andrade (Orgs.), Cocaína e crack: dos fundamentos ao tratamento (p. 15-23). Porto Alegre: Artes Médicas.

Nappo, S. A. (1996). Baqueros e craqueros: Um estudo etnográfico sobre consumo de cocaína na cidade de São Paulo. Tese de Doutorado, Universidade Federal de São Paulo.

Noto, A. R.; Moura, Y. G.; Nappo, S.; Gálduroz, J. C. \& Carlini, E. A. (2002). Internações por transtornos mentais e de comportamento decorrentes de substâncias psicoativas: um estudo epidemiológico nacional do período de 1988 a 1999. Jornal Brasileiro de Psiquiatria, 51(2), 113-121.

Noto, A. R.; Nappo, S.; Galduróz, J. C. F. \& Carlini, E. A. (1997). IV Levantamento sobre o uso de drogas entre crianças e adolescentes em situação de rua de seis capitais brasileiras. São Paulo: Centro Brasileiro de In- formações sobre Drogas Psicotrópicas - CEBRID, Departamento de Psicobiologia, Escola Paulista de Medicina, Universidade Federal de São Paulo.

Weaver, M. F. \& Schnoll, S. H. (1999). Stimulants: Amphetamines and cocaine. Em B. S. McCrady \& E. E. Epstein (Orgs.), Addictions: A comprehensive guidebook (p. 105-120). New York: Oxford University Press.

Weiss, R. D.; Mirin, S. M. \& Bartel, R. L. (1994). Cocaine ( $2^{\mathrm{a}}$ ed.). Washington-DC: American Psychiatric Press.

World Health Organization. (2000). Substance Dependence. Obtido em 19 de abril de 2002 do World Wide Web: http://www.who.int/substance-abuse/more.

Recebido: 14.02 .2002

Revisado: 14.10 .2002

Aceito: 15.10 .2002

\section{Sobre os autores}

Flávia Campos Bahls: Psicóloga, Mestra em Psicologia da Infância e da Adolescência da Universidade Federal do Paraná. Endereço para correspondência: R. Carneiro Lobo, 570/1403, CEP: 80240-240, Curitiba, PR

Saint-Clair Bahls: Psiquiatra, Professor do Departamento de Psicologia da UFPR e da UTP. Mestre em Psicologia da Infância e da Adolescência pela UFPR. E-mail: scbahls@uol.com.br 